OPEN ACCESS

Edited by:

Geneviève Pagé,

University of Quebec in Outaouais,

Canada

Reviewed by:

Jennifer M. Johnson,

Temple University, United States

Jen Stacy,

California State University, Dominguez

Hills, United States

*Correspondence:

Julie Trafford

julie.trafford@aut.ac.nz

Specialty section:

This article was submitted to

Educational Psychology,

a section of the journal

Frontiers in Education

Received: 09 December 2020 Accepted: 14 June 2021

Published: 30 June 2021

Citation:

Trafford J, Haxell A, Lau K, Carlson G

Rebelo da Silva $A P$, Hart $A$,

De Freitas TR and Rope $S$ (2021)

Covid-19 (in) a Class of Its Own:

Student and Teacher Musings

Regarding Their Learnings and WellBeing when Moving a Large Blended

First Year Class Virtually Overnight.

Front. Educ. 6:639466.

doi: 10.3389/feduc.2021.639466

\section{Covid-19 (in) a Class of Its Own: Student and Teacher Musings Regarding Their Learnings and Well-Being when Moving a Large Blended First Year Class Virtually Overnight}

\author{
Julie Trafford *, Ailsa Haxell, Kelvin Lau, Gema Carlson, Ana Patricia Rebelo da Silva, \\ Andrew Hart, Thais Regina De Freitas and Sheridan Rope
}

Auckland University of Technology, Auckland, New Zealand

Covid-19 is (in) a class of its own in its influence on human lives and livelihoods globally, precipitating steep learning and psychological well-being curves for university teachers and students. This has impacted dramatically on the conditions under which higher education has had to function in regard to research and what is now referred to as 'emergency online education'. As staff face unprecedented challenges, so too do students. Given that the consequences of these times are likely to be felt well into the future, it is important to capture what is happening now. We therefore present this perspective piece comprising 13 musings co-authored by students and educators regarding our experiences of two lockdowns within Aotearoa New Zealand in 2020 representative of the disrupted university in its adjustment to learning and teaching. In contributing to calls to develop a post-pandemic pedagogy for higher education, and better support staff and student well-being, we draw on methods that would multiply questions and invoke possibilities, as an impetus for reimagining higher education. Making use of a cogenerative dialoguing process, these musings enable multiple voices to be heard and considered. A non-representational lens enables us to explore the what and how of Covid-19 creating disruption and uncertainty for students' and educators, influencing their psychological well-being and higher education pedagogy and practices, and becoming a contextually relevant taonga (treasure) of experiences that might inform future educational activities.

Keywords: cogenerative dialoguing, Covid-19, flexible learning, higher education, on-line learning

\section{INTRODUCTION}

"We are surrounded by a pragmatic discourse that would have us adapt to the facts of reality" (Freire, 2014, p.1). Our current reality with Covid-19 and the impact this pandemic has had on educational institutions provides an example of a sudden adaptation, unplanned but necessary. In the words of Anderson (2020) Covid-19 necessitates a "pedagogical pivot" into digital learning spaces with unprecedented haste (Veletsianos and Houlden, 2019). This 
occurs in a world of increasing digitalization, with education positioned as anytime anywhere. However, digitalization of education has also been considered problematic (Selwyn, 2010) and challenging (Naidu, 2017). Digital technologies constitute a new context for teaching and learning. While digital technologies are widely utilized within our university, the challenge discussed in this paper is when we are faced with nothing but such technologies mediating the learning and teaching relationship. Drawing on cogenerative dialoguing (Roth and Tobin, 2004) for a process that would open up conversation on experiences as well as making use of Thrift's (2008) non-representational approach, we present what has occurred without a metanarrative. We explore the experiences of educators and students within a large first semester, first year, university course of study in Aotearoa New Zealand; exploring the what and how of learning, teaching and well-being, as was impacted by Covid-19 lockdowns.

\section{Literature Review}

Educators have long been interested in pedagogy as ways of knowing as well as of doing and as educators we are encouraged by Freire's (2014) pedagogy of hope. Our endeavors during such challenging times are hope based in expanding possibilities for social justice. This necessitates creating a liberating, decolonized educational environment, given "there is no change without dreams, as there is no dream without hope" (p. 81). Such critical social theory as pedagogy values open education, self-directed learning and the like. Further, Daniels (2012) reminds us that patterns of social interaction within the cultures of educational institutions allow us to exert a formative effect on the what and how of learnings.

Disruptions to university education in response to Covid-19 have necessitated a pivot into digital pedagogy. Digital pedagogy is not about using digital technologies for learning and teaching per se but rather about approaching digital tools from a critical pedagogical perspective as a means to support desired educational practices and outcomes (Henderson et al., 2017). So, it is about using digital tools thoughtfully, deciding when not to use digital tools, and considering the impact of digital tools on learning (Beetham and Sharpe, 2013). Henderson et al. (2017) note that we need to think about how broader institutional practices and expectations are shaping the what and how of digital technologies in higher education. In this instance this involved a rapid response to the unprecedented reconfiguration required for learning and teaching to be rapidly situated fully online.

\section{Contextualization}

Our university in Auckland, Aotearoa New Zealand has had several decades of infrastructural developments to support elements of distance learning, however, on-line learning has never been the sole approach desired or implemented. While we recognize the values of digital technologies for enhancing learning and teaching, our university has not developed a culture nor identity as a distance education provider. Most of our programmes could never be solely offered online. Graduate profiles, and often professional regulatory bodies, require students undertaking bachelor's in health science, sport and recreation or science to learn how to undertake work with patients, in lab settings, and/or in the field.

In this paper we consider one large, compulsory knowledge, enquiry and communication course for all first-year students in our faculty, which has an enrollment of around 2000 students in first semester and 500 students in second semester. With such numbers, those enrolled reflect a diversity of cultures, ages, educational experiences, etc. Prior to New Zealand's first major Covid-19 outbreak this course occurred both oncampus and on-line using a flipped classroom approach, with only a small cohort of students engaging completely online. Our course has a strong culture of co-learning; educators learning with and from their students; and values diversity also in regard to knowledge construction. In 2020, both offerings of the course began in-person with some hybrid activities. However, by week four, at very short notice-virtually overnight, they were forced to shift completely online. These pedagogical pivots took place when the New Zealand government mandated closure of educational facilities and instructed people to stay at home in their bubble other that if they were essential workers or needed to access essential services.

\section{METHODOLOGY}

Our approach is very much one of aligning with a critical digital pedagogy because we are troubled by how our sudden changes in teaching and learning impact on our educational practices as educators and students. We identify as educators and students with Freire's (2014) pedagogy of hope. Freire called for us to change in how we relate to, and construct knowledge, with others, instead of about them. We aspire to relational, interactive and participatory ways of working even through such unplanned and sudden changes to our learning and teaching practices. As educators we continually evaluate our educational practices; and within this course students are encouraged to reflect on their learning. Making use of cogenerative dialoguing (Roth and Tobin, 2004) our intention is to mobilize improvement in higher education through valuing everyone's input; particularly enhancing the voices and agency of students alongside educators. Such a subversive methodology interrupts power and privilege for reimagining higher education environments, whereby musings are presented with equal importance given to each voice (Stith and Roth, 2006). It brings people together to really listen to one another, accepting both differences and commonalities. Situating ourselves as co-learners and cocreators of knowledge mirrors the learning outcome within the course that situates knowledge as constructed. A key component of our willingness to engage in cogenerative dialoguing is commitment to change (Roth and Tobin, 2004), because of our shared interest in contributing to authentic learning, teaching and curriculum development that would benefit all involved. 
What follows are the musings of educators (Julie. Kelvin, Gema, Sheridan), students (Ana, Andrew, Thais) and our head of school (Ailsa), following two Covid-19 related campus closures and course completion. Sometimes we choose to muse alone, other times in pairs.

This is not a passive stance to the objective enquiry. Invoking Thrift (2014) we raise questions as to future possibilities for a new normal in higher education. Our musings have been ordered through metaloguing (Roth and Tobin, 2004) among all authors and follow a trajectory of course curriculum redesign from what was (Julie's initial musings) through to what might be (Ailsa's musing).

\section{MUSINGS}

\section{Imagining Teaching and Learning Julie}

I felt compelled to redesign the course for semester 12020 , following a workshop with faculty stakeholders regarding contextualization within broader programmes of study. I took this risk one month before the start of semester. I changed learning outcomes, content and assessments. An in-class verbal assessment opportunity, previously identified as challenging by students, was redesigned so students could video and rerecord themselves. Immediacy of change was driven by my desires for assessments more contextualized to students' interests. I was confident in the flexibility of our teaching team. These changes preceded the announcement of Covid-19 as a Global Pandemic. I was oblivious to the serendipity of my decision.

\section{Realities of Context and Pedagogical Pivot Julie}

Requests for flexible learning are not new. For decades, university students have balanced learning, earning and other commitments. Blended learning, through a flipped-classroom, was the old normal in our course. Voluntary weekly on-campus tutorials were designed for teachers to be guides on the side as students completed interactive activities. And, every semester a cohort of distance students studied the course entirely online. So on-line learning was not unfamiliar to our teaching team.

\section{Thais}

As a foreign student, with English not my first language, I didn't know what to expect from the course. I felt like an outsider; unsure and scared. However, I was determined to overcome those feelings and succeed. The first few weeks on campus were dynamic and fun. I was experiencing a different way of learning; interacting with people and feeling confident. It was an enjoyable challenge. However, four weeks into the semester, Covid-19 disrupted everything. New Zealand went into lockdown. AUT moved teaching online. Feelings of uncertainty hit me. Doubts haunted my mind. I am not a computer person, so I faced this challenge on top of everything else. I kept motivated by focusing on my final goal. The first 2 weeks of online teaching were stressful, but to my surprise staff made things easier than I was expecting. I figured out a plan to get through the semester by not allowing procrastination to take place and by keeping the same routine as if I was going into campus. I used the flexibility of studying from home and numerous university resources to keep on top of my work. So, although online learning was not what I signed up for, I still succeeded. It came with a lesson that things can change quickly, and we must adapt to the new situation with the best of our abilities. It is normal to feel scared and unsure. However, focusing on your final goal and reinforcing a plan by using the tools you have available will help you to achieve anything.

\section{Andrew}

Covid-19 was a driver in my successful first year of university. During my first four weeks of on-campus study I struggled to manage time. The first lockdown, and uncertainty around future study, made me quite anxious. As a busy adult student with bills to pay and three years of full-time study ahead of me, the idea of lost time was daunting.

During the break, brought forward by Covid-19, AUT announced we would resume courses from where we had left off-from home. Everything would be online. I swiftly realized that to complete work to a high standard, I would need immense selfdiscipline and focus, by myself, in my home: a place previously allocated for relaxation-university work was to be done in class, or at the library.

Self-motivated learning had never been a strong characteristic of mine. However, as courses progressed, online learning provided far greater flexibility than on-campus study. I was able to spread my workload, use online resources to dig deeper into subjects I struggled with, all at my own pace. I listened to lectures in the garden, while watering plants or weeding vegetables. With recorded material, I could mold my study week to focus on one subject at a time, which suits me incredibly well. After my first A+ result, I realized that online learning, was working for me, and the tough Covid-19 context fueled my urge to succeed.

\section{Ana}

Covid-19 lockdown brought technology challenges when attempting to participate in online tutorials. The internet connection was unreliable. The network sometimes overloaded, hindering my ability to follow conversations and engage.

However, being full time at home allowed more time to study and work without long trips across the city from home to work and to classes. I enjoyed the flexible online tutorial hours. I could attend any or multiple tutorial times. If unable to attend tutorials times, I could refer to recorded tutorials. With flexible work and study hours I accomplished more without compromising the quality of my study or work.

\section{Kelvin}

I was interviewed online and hired as a lecturer during lockdown. My transition to lecturer and joint course coordinator of a large course was marked by rapid increases in responsibilities. This 
role, in uncertain times, was more challenging than I expected. Lockdown meant I was unable to have an orientation. My transition felt like I was thrown in the deep end.

Overcoming my fear of failure to tackle challenges led to opportunities to develop new skills and to innovate. I obtained information about regulations and processes, and advice about being a course coordinator, by asking the right questions and seeking mentorship. This cultivated relationships and opened communication channels with welcoming colleagues. A sense of community developed with online colleagues who I had yet to meet in person.

Close collaboration and agility of our teaching team was vital in the smooth transition into my role. Key strengths of our team were 1) trust to delegate and complete tasks, including management and moderation of up to 40 markers 2) shared enjoyment of team teaching, and willingness to learn from each other and take risks, and 3) empathy for students who were also navigating changes.

\section{Gema and Julie}

Videos allow students to demonstrate creativity and skills in multiple ways. Students submitted an audio-visual file relating to their understanding of knowledge enquiry. Video formats provide formative learning opportunities including self-review, re-recording and editing. This values student agency in developing self-evaluative judgements (Boud et al., 2018). Use of technologies arguably enhance digital literacy. In addition, videos provide a virtual connection with students. We could observe facial expression more clearly than in face-to-face presentations, and had the ability to control volume, pause, slow/increase speed, and re-listen, contributing to fair and reliable marking, and moderation processes.

\section{Julie and Kelvin}

We see Covid-19 as an unprecedented real-world contextually relevant example to thread throughout learning and teaching in health and environmental sciences. By mid-2020 there was no consensus on origins of the virus, its management and impact. In the students' course of study variable claims relating to sources of evidence and how knowledge is constructed could be explored. Over time data and information regarding Covid-19 and its impact continued to emerge, providing real time authentic learning.

We acknowledge that Covid-19 could be a sensitive topic, for teachers and students, especially while still amidst the global pandemic. At the same time, we don't expect teachers or students to ignore or forget what has happened. We discuss Covid-19 as a broad and complex issue that brings together different knowledges (technical, social, political).

\section{Gema and Julie}

Being online challenged identities and engagement of both learners and teachers. We became members of a large online learning community with both synchronous and asynchronous sessions: Gema's pre-existing distance students continued to attend their weekly session online. They remained highly engaged and welcomed new members.
Initial silence of the previously on-campus cohort seemed pronounced online, so we were deliberate to not fill the virtual void as "sages on stage". Online identities, engagement and learning evolved with time: teachers showed their faces, projected their voices and shared resources on screen-Julie even wore silly hats. Students participated by name or pseudonym, chat text, occasionally voice and rarely on camera. We did not restrict students' use of chat, annotation, microphone or video. Students could opt for anonymity. Over time, a collective identity emerged, increasing familiarity and engagement. "Banter" emerged among teachers and learners: sharing experiences and suggestions, reflecting on positives, celebrating achievements, joking, sharing laughter, and making light of technical issues.

\section{Gema}

Practicing kindness and building rapport traverses modes of learning and teaching and is essential to supporting students as they navigate their learning journeys. This provided focus for me during Covid-19. At the outset of each session, I shared something that had happened for me during the week, including a picture. I was the first person to share, promoting a space for others to feel comfortable. I would focus on a common experience and use open ended questions, such as, what is your view like? what got you through this week's lockdown? Students responded using the microphone or chat text. Sharing built trust and rapport. Covid-19 offered opportunities for practices of kindness online.

\section{Julie and Sheridan}

As teachers of first-semester students we prioritize pastoral care. We promote well-being of ourselves and our colleagues. During lockdown we introduced KEC Thrive online synchronous sessions-a partnership of self-care and wellbeing to thrive. We present ourselves, teachers, as real people who too encounter daily challenges, which we can reimagine as possibilities to do things differently. Sheridan shared her own experiences of studying successfully online. Julie shared the turmoil of home becoming spaces of work and learning for her whanau (family). Sheridan's and Julie's fur babies, Jack dog and Shadow cat respectively, made guest appearances.

Some students and teachers spend lockdown alone, physically isolated. KEC Thrive provides a space to converse and connect, to share, listen, compare and empathize with each other's challenges and collaboratively solution-seek.

\section{Reimagining Learning and Teaching Ana}

This experience highlights a need for universities to create a more flexible learning environment where students like me, returning after a long break from formal studies, or individuals looking to retrain while maintaining life responsibilities, can pursue higher education. I often hear from colleagues about their desire to pursue another area of interest but are unable due to the difficulty of balancing work, family and study commitments. Many companies are adopting flexible work environments, enabling 
a less stressful and more balanced life. I hope that flexible work and study environments will continue so I can achieve my dream to prepare for a career that will allow me to do more for society.

These musings are highly insightful. It is interesting to read about the challenges others encountered and how learning and teaching are vastly different experiences for each individual. I wonder if it is not just flexibility that is required in the academic environment, but more customisation.

\section{Ailsa}

It took a pandemic to precipitate questioning of what it is we do and how best we might do it. The interruption to work as planned provoked consideration of educational philosophies and pedagogies. Similarly, this pandemic raised awareness that most everyone experienced unexpected and for some incredible stresses in their lives in their work and in their studies. The collective will to act with kindness and generosity is my takeaway on this. Oddly, I am left musing what is it about higher education or education experiences more generally that make acting with kindness and generosity noteworthy?

I feared for student results, given the stressors they were under and the stressors of my colleagues, and I am surprised at success rates that are higher than in previous years. Generosity and compassion being extended with generous allowance on assessment submission dates provided opportunity for students to submit work in circumstances that were challenging. Again, I'm left reflecting on this. What might we sustain or even extend upon?

Changing an assessment to an audio-visual upload reduced performance anxiety and allowed students to learn while undertaking the assessment task. And so, I ask myself, might learning during an assessment be sustained?

Our faculty did not alter the requirement for all learning outcomes to be achieved on courses, nor did it lower the standards required, or inflate the grades with norm referencing. Standards-based assessment remained in place, with extensions available. I know adult learning theory posits learning as not being a race and of learning being lifelong, yet in a 'normal' year such generosity is a rare consideration.

I remain hopeful of a new "normal".

\section{DISCUSSION AND CONCLUSION}

We engaged in cogenerative dialoguing on a theme toward a cogenerative outcome (Stith and Roth, 2006). Our collective intention was to invite dialogue to share their experiences of university learning and teaching in the context of Covid-19 lockdowns to inform future, as yet unknown, practices for the better. Our musings constitute collective remembering whereby the diversity and integrity of each author's voice is respected, heard, and held rather than disappearing in the collective voice (Roth and Tobin, 2004). We endorse cogenerative dialogue to engage participants in a conversation about their own actions and provide a forum whereby each participant becomes aware of other participant's experiences (Stith and Roth, 2006).

In writing this piece authors engaged in minimal metaloguing (Roth and Tobin, 2004) to order then make some shared meanings of our musings. Our musings collectively follow a trajectory of design through to redesign of university educational processes, and present significant learnings and impacts on psychological well-being for us as educators and students of rapidly moving a blended course to exclusively online. Julie and Gema share the merits of reimagining and redesigning learning and assessments processes.

Andrew and Ana appreciate increased flexibility in their learning.

Ana's technological challenges prompt considerations for issues of equity-a reminder that not everyone is privileged with software, hardware and Internet connectivity.

Kelvin's colleagues provide him with support and assistance through difficult times.

Thais shares grief associated with farewelling face-to-face opportunities. She succeeded and learned of her resilience.

Gema, Julie and Sheridan remind us how kindness and building rapport are fundamental for learning.

Julie and Kelvin thoughtfully incorporate Covid-19 as a contextually relevant topic.

Ailsa echoes Thrift (2014) by raising and multiplying questions, providing a platform to consider possibilities; to find and explore what is uncharted; to attend to things unstable.

Making use of Thrift's (2008) non-representation theory, we emphasize the affective realm. According to Thrift, affective experiences do not lend themselves to meta-dialoguing so, our musings are not subject to privileging, homogenization or reinterpretation by the authors.

Overall, our musings offer some significant learnings and actions in the Covid-19 context that promoted positive educational and well-being outcomes for learners and teachers. Our experiences support the conclusions of other studies (Zhai and Du, 2020; van Niekerk and van Gent, 2021) concerning the importance of university staff and students strengthening resilience and psychological well-being to mitigate the effects of Covid-19 and other future disruptions.

Cogenerative dialoguing holds a commitment to action and to a hoped-for future (Stith and Roth, 2006). Our musings inspire research and other actions. Julie, Ailsa and Gema explore health students' perceptions of the advantages and disadvantages of studying online. Kelvin, Ailsa and colleagues survey teachers' experiences of online teaching. Kelvin tracks science students' and teachers' well-being during Covid-19 related disruption. Julie and Ailsa consider decolonizing pedagogies. Each project engenders hope for a new "normal".

We cherish possibilities that emerge from Covid-19, as a moment of disruption, for reimagining higher education. Our experiences suggest learning and teaching are enhanced where there is a culture of respect, trust, kindness, collegiality, and thoughtfulness among diverse students and educators for our collective purpose. Our musings, research and other actions add to the growing international dialogue as we (re)consider higher education pedagogy within a new-normal. The musings reflect a shift from our pre-pandemic pedagogy of critical social theory to hopefully creating foundations for a post-pandemic critical digital pedagogy.

While universities continue to develop digital resources and improve their reliability and friendliness, at the same time there is a need to think about broader educational practices, specifically 
the what and the how of integrating digital technologies within higher education (Henderson et al., 2017).

We support the calls for post-pandemic higher education pedagogy, one of hope, that is critical and thoughtfully incorporates digital technologies; one that would consider the educational endeavor as relational and inspiring. We frame postpandemic pedagogy as a critical social pedagogy of engagement utilizing technologies for what they add; a critical digital pedagogy. We note that higher pass rates occurred than was the norm of previous semesters/years and although the causative effect of this remains uncertain, we suggest the positive impact on student success is associated with a more conscious use of digital technologies with resource development as well as more thoughtful use of the learning management system. Students benefited from the anywhere anytime access of all teaching resources as well as for connectivity with courses less constrained by time and place. For some students their learning needs were better met, and their unique circumstances better adjusted to where learning was less time constrained by due dates for work. This was all in the context of of greater consideration for support and compassion.

We have never previously been required to collectively consider our purpose and how best to get there; the what and the how being front and centered. We remain hopeful that this thoughtfulness for the what and how, and our working with greater consideration for a relational approach that holds compassion and generosity highly might be sustained within a new "normal" in our learning and teaching endeavors.

\section{REFERENCES}

Anderson, V. (2020). A Digital Pedagogy Pivot: Re-thinking Higher Education Practice from an HRD Perspective. Hum. Resource Dev. Int. 23 (4), 452-467. doi:10.1080/13678868.2020.1778999

H. Beetham and R. Sharpe (2013). Rethinking Pedagogy for a Digital Age. Designing for 21st century Learning. New York, NY: Routledge.

D. Boud, R. Ajjawi, P. Dawson, and J. Tai (2018). Developing Evaluative Judgement in Higher Education Assessment for Knowing and Producing Quality Work. London: Routledge.

Daniels, H. (2012). Institutional Culture, Social Interaction and Learning. Learn. Cult. Soc. Interact. 1 (1), 2-11. doi:10.1016/j.lcsi.2012.02.001

Freire, P. (2014). Pedagogy of Hope : Reliving Pedagogy of the Oppressed. London: Bloomsbury Publishing PLC.

Henderson, M., Selwyn, N., and Aston, R. (2017). What Works and Why? Student Perceptions of 'useful' Digital Technology in university Teaching and Learning. Stud. Higher Educ. 42 (8), 1567-1579. doi:10.1080/03075079.2015.1007946

Fredman, P., \& van't Land, H. (2020) Forward cited in Marinoni, G., van't Land, H., and Jensen, T. (2020). The Impact of Covid-19 on Higher Education Around the World International Association of Universities Global Survey Report. Available at: https://www.iau-aiu.net/IMG/pdf/iau_covid19_and_he_survey_ report_final_may_2020.pdf (Accessed April 14, 2021).

Murphy, M. P. A. (2020). COVID-19 and Emergency eLearning: Consequences of the Securitization of Higher Education for postpandemic Pedagogy. Contemp. Security Pol. 41 (3), 492-505. doi: $10.1080 / 13523260.2020 .1761749$

Naidu, S. (2017). Openness and Flexibility Are the Norm, but what Are the Challenges?. Distance Educ. 38, 1-4. doi:10.1080/01587919.2017.1297185

Roth, W. M., and Tobin, K. (2004). Cogenerative Dialoguing and Metaloguing: Reflexivity of Processes and Genres. Forum Qual. Sozialforschung/Forum Qual. Soc. Res. 5 (3), 1-10. doi:10.1080/0954025032000188017

\section{DATA AVAILABILITY STATEMENT}

The raw data supporting the conclusions of this article will be made available by the authors, without undue reservation.

\section{ETHICS STATEMENT}

Written informed consent was obtained from the individual(s) for the publication of any potentially identifiable data included in this article.

\section{AUTHOR CONTRIBUTIONS}

JT initiated the project and liaised with potential authors who all authored or co-authored at least one musing. Cogenerative dialogue was facilitated by JT. Musings were provided as a focus of the dialogue by JT, AiH, KL, GC, AR, AnH, TDF, and SR. JT and $\mathrm{AiH}$ cogenerated the introduction, methodology, discussion and conclusion, references and abstract.

\section{ACKNOWLEDGMENTS}

We acknowledge all students enrolled in KEC in 2020 and other academic staff facilitating the course. Thank you also to the peer reviewers for the constructive critique provided.

Selwyn, N. (2010). Schools and Schooling in the Digital Age: A Critical Analysis. New York, NY: Routledge.

Stith, I., and Roth, W. M. (2006). Who Gets to Ask the Questions: The Ethics In/of Cogenerative Dialogue Praxis [46 Paragraphs]. Forum Qual. Sozialforschung/Forum Qual. Soc. Res. 7 (2), 1-9. Available at: http://nbn-resolving.de/urn:nbn:de:0114-fqs0602382.

Thrift, N. (2008). Non-representational Theory: Space, Politics, Affect. London: Routledge. doi:10.4324/9780203946565

Thrift, N. (2014). "Summoning Life," in Envisioning Human Geographies. Editors P. Cloke, P. Crang, and M. Goodwin (London: Routledge), 81.

van Niekerk, R. L., and van Gent, M. M. (2021). Mental Health and Well-Being of university Staff during the Coronavirus Disease 2019 Levels 4 and 5 Lockdown in an Eastern Cape university, South Africa. South Afr. J. Psychiatry 27, 1-7. doi:10.4102/sajpsychiatry.v27i0.1589

Veletsianos, G., and Houlden, S. (2019). An Analysis of Flexible Learning and Flexibility over the Last 40 Years of Distance Education. Distance Educ. 40 (4), 454-468. doi:10.1080/01587919.2019.1681893

Zhai, Y., and Du, X. (2020). Addressing Collegiate Mental Health amid COVID-19 Pandemic. Psychiatry Res. 288, 113003. doi:10.1016/j.psychres.2020.113003

Zhao, Y., and Watterston, J. (2021). The Changes We Need: Education post COVID-19. J. Educ. Change 22, 3-12. doi:10.1007/s10833-021-09417-3

Conflict of Interest: The authors declare that the research was conducted in the absence of any commercial or financial relationships that could be construed as a potential conflict of interest.

Copyright (C) 2021 Trafford, Haxell, Lau, Carlson, Rebelo da Silva, Hart, De Freitas and Rope. This is an open-access article distributed under the terms of the Creative Commons Attribution License (CC BY). The use, distribution or reproduction in other forums is permitted, provided the original author(s) and the copyright owner(s) are credited and that the original publication in this journal is cited, in accordance with accepted academic practice. No use, distribution or reproduction is permitted which does not comply with these terms. 